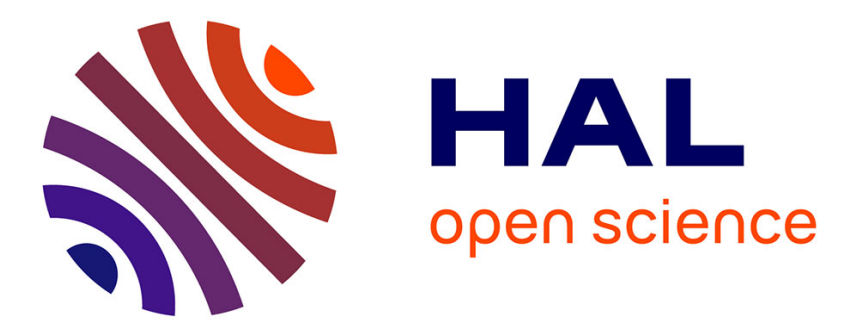

\title{
Environmental Tax Reform under Debt Constraint
}

\author{
Mouez Fodha, Thomas Seegmuller, Hiroaki Yamagami
}

\section{To cite this version:}

Mouez Fodha, Thomas Seegmuller, Hiroaki Yamagami. Environmental Tax Reform under Debt Constraint. Annals of Economics and Statistics, 2018, 129, pp.33 - 52. 10.15609/annaeconstat2009.129.0033 . halshs-01631525

\section{HAL Id: halshs-01631525 \\ https://shs.hal.science/halshs-01631525}

Submitted on 29 Apr 2019

HAL is a multi-disciplinary open access archive for the deposit and dissemination of scientific research documents, whether they are published or not. The documents may come from teaching and research institutions in France or abroad, or from public or private research centers.
L'archive ouverte pluridisciplinaire HAL, est destinée au dépôt et à la diffusion de documents scientifiques de niveau recherche, publiés ou non, émanant des établissements d'enseignement et de recherche français ou étrangers, des laboratoires publics ou privés. 


\title{
Environmental Tax Reform under Debt Constraint
}

\author{
Mouez FoDHA \\ Paris School of Economics, University Paris 1 Panthéon-Sorbonne \\ Thomas SeEgmulLeR \\ Aix-Marseille University, CNRS, EHESS, Centrale Marseille, AMSE \\ Hiroaki YamaGami \\ Seikei University
}

\begin{abstract}
This article analyzes the impacts of Environmental Tax Reform (ETR) when the government is constrained not to increase the public debt-to-output ratio. We consider an overlapping generations model with pollution. Public spending for pollution abatement are financed by tax revenues and public debt. We show that keeping constant the public debt-output ratio is not an obstacle to attain a double dividend, i.e. an increase of both (i) environmental quality and (ii) aggregate consumption. First, if the capital stock is low and the pollution abatement is large enough, a successful ETR consists in a rise of the environmental tax, compensated by a decrease of the income tax. Secondly, we show that the environmental tax revenues may help reduce the public debt-output ratio. We give conditions (on the initial level of the environmental tax and the debtoutput ratio) such that an increase of the environmental tax, budget-balanced by a decrease of the debt-output ratio may also achieve a double dividend. We conclude that public debt crisis should not compromise ETR, instead, environmental tax revenues could be part of the solution.*
\end{abstract}

\section{Introduction}

The growing environmental concerns motivate the European countries to adapt their tax structure by introducing new taxes on pollutants. These tax revenues are used to limit the distortions by reducing other taxes, otherwise they are allocated to pollution abatement sectors. The allocation decision is guided by fiscal objectives which impose to control public deficits and public debt. Indeed, high levels of public debt can be a barrier for launching environmental programs if they exacerbate government deficits. This was likely to be the case in Europe during the global debt crisis that started in 2007.

*JEL: Q5, H23, H63 / KEY WORDS: Environmental Tax Reform, Debt, Public Emission Abatement, Double Dividend, Overlapping Generations Model. 
In this article, we study the impacts of Environmental Tax Reform (ETR) under a debt constraint, when public actions to protect the environment are financed by public funds. Could a public debt stabilization objective be an obstacle to the success of ETR? Conversely, could the environmental tax revenues reduce the public debt and protect the environment?

We consider an overlapping generations (OLG) model with pollution externalities. Production deteriorates the environmental quality, harming the welfare of future generations. Public spending for pollution abatement is financed by taxation and public debt, but the government is constrained not to increase the public debt-to-output ratio.

We show that the level of capital stock and the pollution abatement are the key factors that explain the consequences of the ETR. Namely, if the capital stock is low and the public pollution abatement is large enough, an increase of the environmental tax, compensated by a decrease of the income tax, may yield a double dividend, defined as an increase of both (i) the environmental quality and (ii) the aggregate households' consumption. We also find that an increase of the environmental tax budget-balanced by a decrease of the debtoutput ratio may attain a double dividend. The intuitions of the main mechanisms at work are the following. The direct impact of an increase of the environmental tax rate is a rise in the tax revenues. To maintain the budget balanced, the government can compensate this increase by a decrease of the labor tax rate or a decrease of the debt-output ratio. This evolution of the tax system increases net incomes and savings, which rises the capital stock and wages, leading to a rise of aggregate consumption. In addition, a higher capital stock induces a drop of the interest rate, which reduces the debt reimbursement burden in the future. Finally, maintaining a sufficiently high level of public spending ensures pollution mitigation. Accordingly, public debt constraint should not compromise ETR, instead, environmental tax revenues could be part of the solution.

Our findings confirm the empirical results of Rausch, S. [2013]. Using an OLG dynamic general equilibrium model of the U.S. economy, Raush shows that when a carbon tax is employed to consolidate public debt, the environmental policies could generate sustained welfare gains for future generations. However, we differ from RAuSCH, S. [2013] by first considering a simple theoretical model (one aggregate sector) which allows for complete analytical solving and clear explanations of the transmission channels. Raush considers a multi-sectoral production structure including intermediate production, with specific details on the energy sector. Secondly, we take into account pollutant emissions and pollution mitigation to shed light on the intergenerational environmental externalities, whereas Raush's article focuses on energy consumptions, prices and incomes, and do not consider any pollution externalities.

Whether an ETR can be designed without negatively affecting the economic welfare has given rise to a huge literature. As governments use the revenues from pollution taxes to decrease other distortionary taxes, environmental taxes may lead to a double dividend ${ }^{1}$

1. More generally, the double dividend is defined as (i) an improvement of the environmental quality and (ii) a decrease of the distortions induced by the tax system. Actually, depending on the context, there exist many interpretations of the second dividend, like the increase of GDP, employment, private consumption... In our article, we will assume aggregate consumption as a good proxy of this dividend. 
(GOULDER, L.H. [1995]). In addition, environmental decisions have an impact on the welfare of both current and future generations. These intergenerational issues on environmental externalities and taxation have been already studied. For instance, BovenberG, A.L., and B.J. HEIJDRA [1998] examine the effects of a green tax on polluting capital when the tax revenue is redistributed by lump-sum intergenerational transfers. This literature generally concludes that a double dividend can be obtained at the expense of equity (Proost, S., and D. Van Regemorter [1995], Bovenberg, A.L., and F. van der Ploeg [1996], Bosello, F., et al. [2001], Chiroleu-Assouline, M., and M. Fodha [2005], Chiroleu-Assouline, M., and M. Fodha [2006] and Chiroleu-Assouline, M., and M. Fodha [2014]).

Furthermore, debt financing has been introduced in dynamic models with environmental concerns (Bovenberg, A.L., and B.J. Hejdra [1998]; Heijdra, B.J., et al. [2006], FERnÁndEz, E., et al. [2010]). Debt policy only makes possible to redistribute welfare gains from future to existing generations: there is no debt financing of the pollution mitigation sectors. FodHa, M., and T. SEegmulLer [2012] analyze the consequences of ETR under a public debt stabilization constraint with public abatement industry. ${ }^{2}$ But, the households also invest in private pollution abatement.

In this paper, we rather analyze the interactions between the public debt consolidation objective and environmental policies when pollution abatement is a public sector, financed by tax revenues and debt emission. We examine whether a revenue-neutral increase in the pollution tax compensated by a change of the tax system can yield a double dividend, and benefits all generations.

The rest of this paper is organized as follows. SEction II presents the OLG model with environmental externalities. SECTION III defines the intertemporal equilibrium and examines the properties of the steady states. SECTION IV studies the impacts of an increase of the environmental tax balanced through a decrease of the income tax. SECTION V presents the consequences of an ETR balanced by a decrease of the debtoutput ratio. The final section provides the conclusions.

\section{The Model}

We consider an overlapping generations model with discrete time $(t=0,1, \ldots,+\infty)$, capital accumulation, and environmental quality which degrades with production, but may be improved by public abatement, financed by tax revenues or public debt.

\section{II.1. Household}

At each period, a new generation is born. There is no population growth and population size of a generation is normalized to $N>0$. Individuals live for two periods: young and old. The young born in period $t$ have preferences over their consumption bundle when

2. In a similar framework, FodHa, M., and T. SEegmuller [2014] consider the impacts of pollution on life expectancy. 
young $\left(c_{t}\right)$ and old $\left(d_{t+1}\right)$, and environmental quality when young $\left(E_{t}\right)$ and old $\left(E_{t+1}\right)$. $E_{t}$ is an externality for the household. The life-cycle utility is given by:

$$
\ln c_{t}+\gamma v\left(E_{t}\right)+\beta\left(\ln d_{t+1}+\gamma v\left(E_{t+1}\right)\right)
$$

where $\beta \in(0,1)$ is the discount factor, $\gamma>0$ the relative weight of the environmental quality and $v($.$) measures the welfare gains from the environmental quality. The young$ born in period $t$ inelastically supplies one unit of labor and receives real wage $\left(w_{t}\right)$. An income tax $\left(\tau_{t}^{w}\right)$ is imposed on the real wage and the after-tax income is shared between present consumption and savings $\left(s_{t}\right)$.

When old, the household is retired and entirely consumes the remunerated savings $\left(r_{t+1} s_{t}\right)$ where $r_{t+1}$ is the real interest rate. ${ }^{3}$ Budget constraints of an individual born in period $t$ are given by:

$$
c_{t}+s_{t}=\left(1-\tau_{t}^{w}\right) w_{t}, \quad d_{t+1}=r_{t+1} s_{t} .
$$

Then, the savings function is derived as:

$$
s_{t}=\frac{\beta}{1+\beta}\left(1-\tau_{t}^{w}\right) w_{t} .
$$

Because labor is inelastically supplied, the income tax does not distort labor market. Nevertheless, the income tax distorting labor supply has been repeatedly examined in static general equilibrium models since Bovenberg, A.L., and R.A. DE Mooij [1994] and PARRY, I.W.H. [1995]. In our model, the income tax affects savings and thereby capital accumulation. We focus on the dynamic effects of taxation, through savings, rather than static distortions that affect the labor market.

Our ETR consists in an increase of the pollution tax compensated by a decrease of the income tax rate or by a decrease of the debt-output ratio. Conditions for a successful double dividend achievement rely on the final impacts of the ETR on the tax distortions (which may increase because of environmental taxation) relatively to the impacts on the pollution externality (which has to decrease). Taking account of distortionary taxes on labor by assuming endogenous labor supply for instance would probably facilitate the conditions that have to be reached to obtain the double dividend. Indeed, the ETR would imply a higher decrease of the labor taxation due to the increase of labor supply, in order to balance the government budget, therefore reducing the total distortions of the tax structure.

3. We assume complete depreciation of capital. Since the period length is quite long in overlapping generations model with two-period lived households, this assumption is not restrictive. 


\section{II.2. Firms}

A representative firm produces the unique good using a Cobb-Douglas technology:

$$
Y_{t}=K_{t}^{\alpha} L_{t}^{1-\alpha},
$$

where $Y_{t}, L_{t}$, and $K_{t}$ are output, labor, and capital stock, respectively. The intensive production function is given by $y_{t}=k_{t}^{\alpha}$, where $k_{t}$ and $y_{t}$ are per worker capital stock and output. Production process emits pollution as by-products and, therefore, government imposes an environmental tax $\left(\tau^{e}\right)$ on its product sales. Taking the output price as numeraire, profits write $\left(1-\tau^{e}\right) Y_{t}-w_{t} L_{t}-r_{t} K_{t}$. The first order conditions for profit maximization are:

$$
\begin{aligned}
w_{t} & =\left(1-\tau^{e}\right)(1-\alpha) k_{t}^{\alpha} \\
r_{t} & =\left(1-\tau^{e}\right) \alpha k_{t}^{\alpha-1} .
\end{aligned}
$$

\section{II.3. Government}

The government imposes taxes on income and sales. In addition public debt $\left(B_{t}\right)$ allow to finance a share of pollution abatement $\left(G_{t}\right)$. The government budget constraint is:

$$
B_{t}=r_{t} B_{t-1}-\left(\tau_{t}^{w} w_{t} N+\tau^{e} Y_{t}\right)+G_{t},
$$

with $B_{-1} \geqslant 0$ given.

To avoid explosive debt path, we assume that the government spending-output $G_{t} / Y_{t}$ and debt-output $B_{t} / Y_{t}$ ratios are constant over time, i.e. equal to $g \geqslant 0$ and $\delta \geqslant 0$, respectively (see also DE LA Croix, D., and P. Michel [2002]). The budget constraint writes:

$$
\delta Y_{t}=r_{t} \delta Y_{t-1}-\left(\tau_{t}^{w} w_{t} N+\tau^{e} Y_{t}\right)+g Y_{t} .
$$

In line with the double dividend literature, we do not analyze the optimal tax system. Seeking for optimality would require to take into account the intergenerational externality on capital accumulation (dynamic efficiency) and the environmental externality. Given a level of abatement per output, we combine two policy instruments in order to (partially) decrease the distortions. Our ETRs consist in an increase of $\tau^{e}$ compensated by either $(i)$ a decrease of $\tau^{w}$ or (ii) a decrease of the debt-output ratio $\delta$ to obtain a double dividend.

\section{II.4. Environmental Quality}

Pollution occurs through production processes while the government spends on emission abatement. The law of motion of the environmental quality index is:

$$
E_{t+1}=(1-\eta) E_{t}+\theta G_{t}-\varepsilon Y_{t}, \text { with } E_{0} \text { given, }
$$


where $\varepsilon>0, \theta>0$, and $\eta \in(0,1)$ are efficiency parameters measuring the pollution emission from production, the public emission abatement, and the capacity to converge to the natural environmental quality in the absence of any pollution flow.

To keep things simple, as we deal with a one sector aggregate output, we assume that production is the unique source of pollution (even if it is only a proxy). We also assume $\theta$ and $\varepsilon$ to be constant, meaning that we do not consider any green innovation for instance. Actually, emissions of many pollutants per unit of output have declined over time in developed countries with increasingly stringent environmental regulations and technical innovations. But, in the same time, the mix of pollutants has shifted from some pollutants to carbon dioxide, biodiversity loss and other solid waste, so that aggregate pollution is still high. Our environmental index is supposed to reflect the pollutants diversity.

\section{Equilibrium, Steady States and Dynamics}

The labor market equilibrium writes $N=L_{t}$, for all $t$. Therefore, environmental quality per young agent $e_{t} \equiv E_{t} / N$ satisfies:

$$
e_{t+1}=(1-\eta) e_{t}+(\theta g-\varepsilon) k_{t}^{\alpha}
$$

and the government budget constraint rewrites:

$$
\delta y_{t}=r_{t} \delta y_{t-1}-\left(\tau_{t}^{w} w_{t}+\tau^{e} y_{t}\right)+g y_{t} .
$$

In this section, we consider that $g, \delta$ and $\tau^{e}$ are kept constant over time and the government adjusts the income tax rate $\tau_{t}^{w}$ to balance its budget. Therefore, this tax rate is endogenously determined by:

$$
\tau_{t}^{w}=\left[r_{t} \delta y_{t-1}-\left(\tau^{e}+\delta-g\right) y_{t}\right] / w_{t}
$$

By substituting $\tau_{t}^{w}$ in the capital market equilibrium, we obtain a tractable reduced form of the intertemporal equilibria, where $g, \delta$ and $\tau^{e}$ are policy parameters.

The market-clearing condition for capital market is: ${ }^{4}$

$$
k_{t+1}=s_{t}-\delta y_{t} .
$$

We substitute (1) and the equilibrium prices (2) and (3) to determine an intertemporal equilibrium. Following DE LA CRoIX, D., and P. Michel [2002], we define the investment factor $z_{t+1} \equiv k_{t+1} / k_{t}^{\alpha}$, equal to the ratio of investment ${ }^{5}$ over output.

4. The capital stock in period $t+1$ is equal to the young individuals' savings in period $t$ minus the public debt in $t$. Since the labor market also clears, the equilibrium in the goods market, $y_{t}=c_{t}+d_{t}+k_{t+1}+g y_{t}$, is satisfied by the Walras' law.

5. Investment $I_{t}$ respects the standard accumulation equation: $K_{t+1}=(1-\mu) K_{t}+I_{t}$, where $\mu$ is the constant depreciation rate. As there is complete depreciation of capital $(\mu=1)$, we have $K_{t+1}=I_{t}$. 
Making this variable substitution reduces the size of the dynamic system that governs the dynamics to a one-dimensional equation. Indeed, (6) can be rewritten as:

$$
z_{t+1}=\phi\left(z_{t}\right)=\frac{\beta\left[1-g-\left(1-\tau^{e}\right) \alpha\right]-\delta}{1+\beta}-\frac{\alpha \beta \delta}{1+\beta} \frac{1-\tau^{e}}{z_{t}}
$$

By direct inspection of this equation, we see that $z_{t}>0$ for all $t$ requires $\beta\left[1-g-\left(1-\tau^{e}\right) \alpha\right]>\delta$. This condition implies that the public debt-output ratio should not be too large, in order limit the crowding-out effect. Otherwise, if $\delta$ moves beyond the threshold, public debt could absorb the whole flow of private savings, leading to a fall in capital stock.

We are now able to define an intertemporal equilibrium:

Definition 1. If $\beta\left[1-g-\left(1-\tau^{e}\right) \alpha\right]>\delta$, an intertemporal equilibrium is characterized as a sequence of strictly positive investment factors $\left(z_{t}\right)_{t=1}^{\infty}$, satisfying (7), given $z_{0}>0$.

Dynamics are driven by a one-dimensional dynamic system, where $z_{t}$ is a predetermined variable. Note that $z_{0}=k_{0} / k_{-1}^{\alpha}$ given implies two initial conditions $k_{0}$ and $k_{-1}$. In fact, the second initial condition comes from the initial one on debt $B_{-1} \geqslant 0$ and the constant debt-output ratio $B_{t} / Y_{t}=\delta$. Given the sequence $\left(z_{t}\right)$, we are able to determine the sequence of per worker capital stock $\left(k_{t}\right)$ defined by $k_{t+1}=z_{t+1} k_{t}^{\alpha}$. Finally, given $\left(k_{t}\right)$, one deduces the dynamics of $\left(e_{t}\right)$ using (4).

The steady-state investment factors are solutions to:

$$
P(z)=z^{2}-\frac{\beta\left[1-g-\left(1-\tau^{e}\right) \alpha\right]-\delta}{1+\beta} z+\frac{\alpha \beta \delta\left(1-\tau^{e}\right)}{1+\beta}=0 .
$$

The corresponding stationary level of capital $(k)$ and environmental quality $(e)$ per capita are given by:

$$
\begin{aligned}
& k=z^{\frac{1}{1-\alpha}} \\
& e=\frac{\theta g-\varepsilon}{\eta} z^{\frac{\alpha}{1-\alpha}} .
\end{aligned}
$$

Steady states and dynamics are characterized in the following proposition:

Proposition 1. Assuming $g<1-\alpha$, there exists $\bar{\delta}>0$ such that, when $\delta \in[0, \bar{\delta})$, there are two steady states, an unstable one $\underline{z}$ and a stable one $\bar{z}$, given by:

$$
\underline{z}=\frac{\beta\left[1-g-\left(1-\tau^{e}\right) \alpha\right]-\delta-\sqrt{\left\{\beta\left[1-g-\left(1-\tau^{e}\right) \alpha\right]-\delta\right\}^{2}-4(1+\beta)\left(1-\tau^{e}\right) \alpha \beta \delta}}{2(1+\beta)}
$$




$$
\begin{aligned}
\bar{z} & =\frac{\beta\left[1-g-\left(1-\tau^{e}\right) \alpha\right]-\delta+\sqrt{\left\{\beta\left[1-g-\left(1-\tau^{e}\right) \alpha\right]-\delta\right\}^{2}-4(1+\beta)\left(1-\tau^{e}\right) \alpha \beta \delta}}{2(1+\beta)} \\
& \equiv \zeta\left(\tau^{e}, g, \delta\right) .
\end{aligned}
$$

When $\delta=\bar{\delta}$, a saddle-node bifurcation occurs and no steady state exists when $\delta>\bar{\delta}$

Proof. The existence of two steady states requires that the discriminant of $P(z)$ must be positive, i.e.

$$
\begin{aligned}
& {\left[\beta\left(1-g-\left(1-\tau^{e}\right) \alpha\right)-\delta\right]^{2}-4 \alpha \beta \delta(1+\beta)\left(1-\tau^{e}\right)>0 \Leftrightarrow \delta^{2}-2 \beta[1-g} \\
& \left.-\left(1-\tau^{e}\right) \alpha+2 \alpha(1+\beta)\left(1-\tau^{e}\right)\right] \delta+\left[\beta\left(1-g-\left(1-\tau^{e}\right) \alpha\right)\right]^{2}>0 .
\end{aligned}
$$

By direct inspection of equation (8), we note that the existence of steady states requires $\delta<\beta\left(1-g-\left(1-\tau^{e}\right) \alpha\right)$. This may be fulfilled for $g<1-\alpha$. We deduce that there exist two steady states if and only if $\delta<\bar{\delta}$, with:

$$
\begin{gathered}
\bar{\delta}=\beta\left[1-g-\left(1-\tau^{e}\right) \alpha+2 \alpha(1+\beta)\left(1-\tau^{e}\right)\right] \\
-2 \beta \sqrt{\alpha(1+\beta)\left(1-\tau^{e}\right)\left[1-g-\left(1-\tau^{e}\right) \alpha+\alpha(1+\beta)\left(1-\tau^{e}\right)\right]} .
\end{gathered}
$$

The two steady states are given by (11) and (12). When $\delta=\bar{\delta}$, the two steady states merge, and disappear for $\delta>\bar{\delta}$.

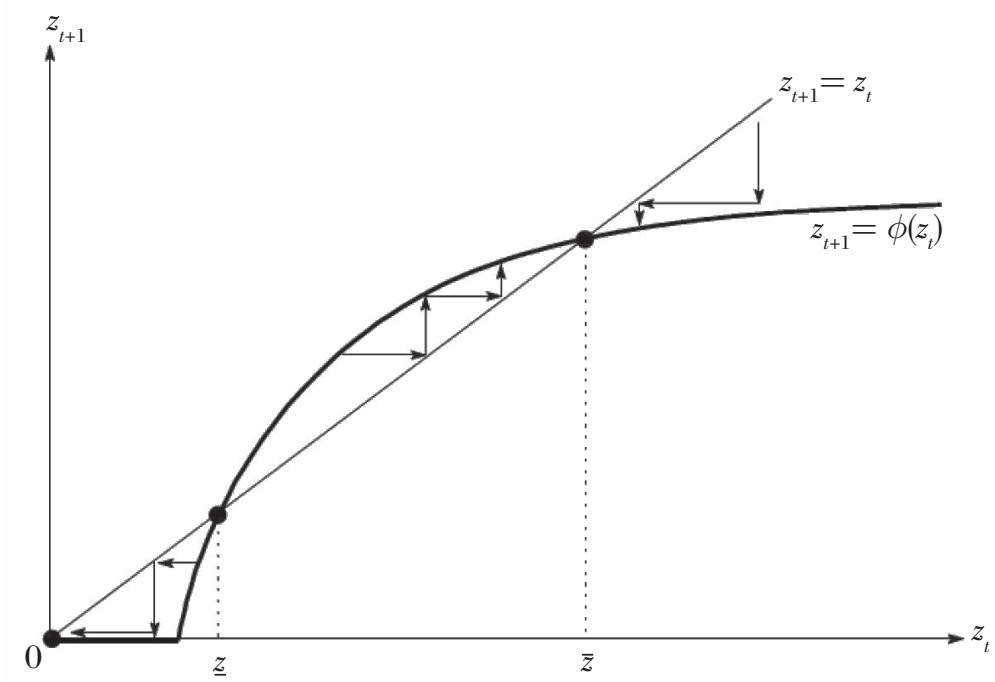

Figure 1. - Dynamics with Two Steady States 
We deduce the stability properties from the features of $\phi\left(z_{t}\right)$, given by equation (7). Since

$$
\begin{aligned}
& \lim _{z_{t} \rightarrow 0} \phi\left(z_{t}\right)=-\infty, \lim _{z_{t} \rightarrow+\infty} \phi\left(z_{t}\right)=\frac{\beta\left[1-g-\left(1-\tau^{e}\right) \alpha\right]-\delta}{1+\beta}>0, \\
& \phi\left(z_{t}\right)^{\prime}>0, \phi\left(z_{t}\right)^{\prime \prime}<0,
\end{aligned}
$$

the lower steady state is unstable, whereas the larger one is stable (see FigurE 1).

Note that condition $g<1-\alpha$ is standard and not too restrictive. With our specifications, it reflects the fact that the labor income is not entirely devoted to finance public abatement, whatever is the level of the environmental tax rate.

The configuration where there are two steady states $(\delta<\bar{\delta})$ is represented in Figure 1 . The lower steady state $\underline{z}$ is unstable, while the higher one $\bar{z}$ is stable. Therefore, for $z_{t}$ lower than $\underline{z}$, the economy is relegated to a low-income "poverty trap", where $z_{t}$ decreases to 0 . Otherwise, the economy converges to the steady state $\bar{z}$. Note that since $k_{t+1}=z_{t+1} k_{t}^{\alpha}$, the convergence of the investment factor to a stationary value corresponds to the convergence of the capital stock $k_{t}$ to its steady state level.

In the next sections, we analyze the effect of fiscal policies on a long-run steady state. Because $z_{t}$ is a predetermined variable, we focus on the stable steady state $\bar{z}{ }^{6}$ We are interested in the possible improvement of both environmental quality and macroeconomic variables of the model. Besides an increase in the amount of environmental quality per capita, we are concerned with an increase in the total amount of consumption per capita $\bar{C} \equiv \bar{c}+\bar{d}$, called "macroeconomic effect". Instead of measuring the individual welfare (aggregate measure), we consider separately the environmental variations (usually called first dividend) and the economic side (second dividend). As we mainly focus on capital accumulation and distortions from the preexisting taxes, capital stock or total consumption are both good indicators of the economic outcome.

Using (10), we deduce the link between environmental quality and the investment factor or the capital stock. It depends on the sign of $\theta g-\varepsilon$, which measures the evolution of the net flow of anthropogenic pollution. When $\theta g-\varepsilon$ is positive for example, pollution abatement is higher than pollutants emission flow.

To evaluate the link between the total amount of consumption per capita and the capital stock, we need to investigate whether there is or not capital under-accumulation.

Using the resource constraint $\bar{y}=\bar{c}+\bar{d}+\bar{k}+g \bar{y}, \bar{C}$ is given by:

$$
\bar{C}=(1-g) \bar{k}^{\alpha}-\bar{k}
$$

6. To clarify notations, $\bar{x}$ will denote in the following the value of the variable $x_{t}$ evaluated at the steady state $\bar{z}$. 
Given the government policy, $\bar{C}$ is maximized for $\bar{k}=\bar{k}_{g}$, with:

$$
\bar{k}_{g}=[\alpha(1-g)]^{\frac{1}{1-\alpha}} .
$$

From (9), the stationary investment factor corresponding to $\bar{k}_{g}$ is $\bar{z}_{g}=\alpha(1-g)$. Because $\partial \zeta\left(\tau^{e}, g, \delta\right) / \partial \delta<0$ for all $\delta<\bar{\delta}$ (see equation (12)), there exists at most a unique debt-output ratio $\delta=\delta_{g}$ that corresponds to the maximized level of total consumption per capita ${ }^{7}$ :

$$
\zeta\left(\tau^{e}, g, \delta_{g}\right)=\bar{z}_{g}=\alpha(1-g)
$$

We deduce that there is under-accumulation if and only if $\delta>\delta_{g}$.

Proposition 2. Assuming $\delta \in[0, \bar{\delta}), g<1-\alpha$ and $\frac{\beta}{1+\beta}<4 \alpha(1-\alpha)$, there is under-accumulation of capital at the steady state $\bar{z}$ if $\delta \in\left(\delta_{g}, \bar{\delta}\right)$.

Proof. The steady state $\bar{z}$ is characterized by under-accumulation if $\delta>\delta_{g}$, but $\delta<\bar{\delta}$ is required for its existence. Hence, we need to have $\delta_{g}<\bar{\delta}$, which is equivalent to $\zeta\left(\tau^{e}, g, \delta_{g}\right)>\zeta\left(\tau^{e}, g, \bar{\delta}\right)$. Using (12) and (16), this inequality rewrites $\bar{\delta}>\beta\left[1-g-\left(1-\tau^{e}\right) \alpha\right]-2(1+\beta) \alpha(1-g)$. Substituting (13), it is equivalent to $P\left(1-\tau^{e}\right)>0$, with:

$$
\begin{aligned}
P\left(1-\tau^{e}\right) \equiv & \alpha \beta^{2}\left(1-\tau^{e}\right)^{2}+\beta(1-g)[2 \alpha(1+\beta)-\beta]\left(1-\tau^{e}\right) \\
& +\alpha(1+\beta)(1-g)^{2} .
\end{aligned}
$$

The discriminant of this polynomial of degree 2 is given by $\beta^{3}(1-g)^{2}[\beta-4 \alpha(1-\alpha)(1+\beta)]$. When $\frac{\beta}{1+\beta}<4 \alpha(1-\alpha), \quad$ it $\quad$ is negative, which shows that $P\left(1-\tau^{e}\right)>0$ for all $\tau^{e}$. This ensures that $\delta_{g}<\bar{\delta}$. Therefore, for $\delta \in\left(\delta_{g}, \bar{\delta}\right)$, the steady state $\bar{z}$ is characterized by under-accumulation.

Proposition 2 shows that a not too low level of the debt-output ratio ensures under-accumulation of capital. To address the plausibility of this result, it is relevant to observe that the savings rate $\beta /(1+\beta)$ is smaller than $1 / 2$, while under standard parametrization, the capital share in income $\alpha$ belongs to $(1 / 4,1 / 2)$. In this case, the inequality $\frac{\beta}{1+\beta}<4 \alpha(1-\alpha)$ is fulfilled. Finally, note that $\tau^{e} \leqslant 1-\frac{1-g}{\alpha \beta}[\beta-\alpha(1+\beta)]$

7. From (9), we also have $\bar{z}_{g}=\bar{k}_{g}^{1-\alpha}$. 
means that $\zeta\left(\tau^{e}, g, \delta_{g}\right) \geqslant \zeta\left(\tau^{e}, g, 0\right)$ which is equivalent to $\delta_{g} \leqslant 0:$ the relevant interval for under-accumulation becomes $(0, \bar{\delta})$.

Using these preliminary results that have established the link between, on the one hand, environmental quality and capital and, on the other hand, the total amount of consumption per capita and capital, we investigate now some environmental policies that have positive environmental and macroeconomic effects, i.e. improve both $\bar{e}$ and $\bar{C}$. Given an appropriate level of public abatement per output $g$, an environmental policy is characterized by an increase of the environmental tax rate $\tau^{e}$. The government budget constraint, evaluated at the steady state $\bar{z}$, writes:

$$
\tau^{w}=\frac{\alpha}{1-\alpha} \frac{\delta}{\bar{z}}+\frac{g-\tau^{e}-\delta}{\left(1-\tau^{e}\right)(1-\alpha)}
$$

This condition will be fulfilled if either the tax rate on labor income $\tau^{w}$ or the debtoutput ratio $\delta$ varies following an increase of $\tau^{e}$. We investigate these two policies in the next two sections.

\section{ETR Balanced by Labor Income Taxation}

We are interested in the effect of an increase of environmental taxation, given that public spending-output and debt-output ratios are constant. Therefore, labor income tax will adjust to balance the public budget, modifying the level of the investment factor. We will focus on a possible improvement of both environmental and macroeconomic variables, i.e. environmental quality and aggregate consumption.

Proposition 3. Assume that $\delta$ and $g$ do not vary, $g<1-\alpha$ and $\frac{\beta}{1+\beta}<4 \alpha(1-\alpha)$. Following a rise of the environmental tax rate $\tau^{e}$, the investment factor $\bar{z}$ increases, while the labor income tax rate $\tau^{w}$ decreases. This ETR produces positive environmental and macroeconomic effects if and only if:

(i) The public emission abatement over output is large enough, i.e. $g>\varepsilon / \theta ;^{8}$

(ii) There is under-accumulation, i.e. $\delta \in\left(\delta_{g}, \bar{\delta}\right)$.

Proof. We start by studying the effect of an increase of $\tau^{e}$ on the steady state investment factor $\bar{z}$. Differentiating (12), we obtain:

$$
\left.\frac{d \bar{z}}{d \tau^{e}}\right|_{d \delta=d g=0}=\frac{\alpha \beta(\bar{z}+\delta)}{\sqrt{\left\{\beta\left[1-g-\left(1-\tau^{e}\right) \alpha\right]-\delta\right\}^{2}-4 \alpha \beta \delta\left(1-\tau^{e}\right)(1+\beta)}}>0
$$

8. Recall that this condition implies a negative net flow of anthropogenic pollution. 
The steady state income tax rate is derived as a function of other policy instruments from the government budget constraint (17). Indeed, substituting $\bar{z}=\zeta\left(\tau^{e}, g, \delta\right)$, it can be defined as $\tau^{w} \equiv \tau\left(\tau^{e}, g, \delta\right)$. We obtain:

$$
\left.\frac{d \tau^{w}}{d \tau^{e}}\right|_{d g=d \delta=0}=-\frac{1}{(1-\alpha)\left(1-\tau^{e}\right)}\left(\frac{1-g+\delta}{1-\tau^{e}}+\frac{\alpha\left(1-\tau^{e}\right) \delta}{\bar{z}^{2}} \frac{\partial \zeta(\cdot)}{\partial \tau^{e}}\right)<0 .
$$

Now, we can derive the conditions to get the environmental and macroeconomic effects. Differentiating (10), we obtain:

$$
\left.\frac{d \bar{e}}{d \tau^{e}}\right|_{d \delta=d g=0}=\left.\frac{\alpha(\theta g-\varepsilon)}{\eta \bar{z}} \frac{d \bar{k}}{d \tau^{e}}\right|_{d \delta=d g=0}
$$

From (9) and (18), the positive environmental effect is obtained if and only if the public emission abatement over output is large enough, that is, $g>\varepsilon / \theta$.

Differentiating now (14), and using (9) and (15), we have:

$$
\left.\frac{d \bar{C}}{d \tau^{e}}\right|_{d \delta=d g=0}=\left.\frac{(\bar{z})^{\frac{\alpha}{1-\alpha}}}{1-\alpha}\left(\frac{\bar{z}_{g}}{\bar{z}}-1\right) \frac{d \bar{z}}{d \tau^{e}}\right|_{d \delta=d g=0}
$$

From (18), the positive macroeconomic effect is obtained if and only if $\bar{z}<\bar{z}_{g}$, i.e. if $\delta \in\left(\delta_{g}, \bar{\delta}\right)$.

The environmental tax, in principle, imposes additional costs on polluting behavior, which could a priori be harmful for the steady state investment factor. Indeed, such a tax increases the costs faced by the firm on its inputs use. However, recycling revenues provided from the increase of the environmental tax rate leads to lower income tax rates. Because the latter effect is greater than the former on savings, this ETR will increase the steady state investment factor. Considering the government budget, note that the decrease of $\tau^{w}$ comes from two direct effects and a general equilibrium effect. The first direct effect is explained by the increase of government revenue coming from a larger environmental tax rate. The second direct effect goes through the fact that a higher environmental tax rate decreases the interest rate. Indeed, the environmental tax is a tax on output, which has a direct negative effect on the return of capital (see (3)). Finally, the general equilibrium effect goes in the same direction: a higher level of capital induces a decrease in the interest rate. This leads to a smaller amount of debt reimbursement in the future and, thereby, it lowers the income tax rate.

The ETR cuts the personal income tax, allowing a larger level of capital per capita. This raises aggregate consumption when there is under-accumulation, explaining the macroeconomic effect. Note that the requirement of under-accumulation of capital seems to be quite realistic, since this is equivalently ensured by a not too low real interest rate, which is experienced by most developed countries in the last decades. Recall that 
under-accumulation also means dynamic efficiency, which is a feature supported by the findings of ABEL, A., et al. [1989]. Public emission abatements play an important role for the environmental effect. The public spending-output ratio $g$ or efficiency of public emission abatements $\theta$ has to be large enough to ensure negative pollution flows. In this case, environmental quality is positive at the steady state and positively varies with the level of capital.

Because the ETR positively affects the steady-state investment factor $\bar{z}$, the conditions for the double dividend differ from those in the literature. For instance, ONo, T. [2005] considers an ETR that cuts the social security tax in the absence of public emission abatement. Therefore, the environmental dividend is produced only when the capital per capita decreases. Moreover, the non-environmental dividend is obtained because there is over-accumulation at the steady state and capital per worker decreases.

Remarks on the Distributive Issues. Our analysis has also direct implications on the distributive issues. Assuming that the steady state $\bar{z}$ satisfies the conditions for a successful ETR (i.e. Proposition 3 verified), could this tax policy be detrimental for some generations and/or for consumption at some periods? Can we determine which generations will benefit from the ETR?

At the first period (i.e. when the tax policy is implemented), the increase of investment implies a decrease of aggregate consumption, because capital and therefore production, are predetermined. In contrast, we have shown that the fiscal policy is beneficial for investment at the steady state towards which the economy converges. Because there is under-accumulation of capital and by continuity, the increase of the sequence of capital is first damaging for aggregate consumption and, after some date, improves consumption. ${ }^{9}$

Intergenerational environmental externalities and taxation issues have already been studied (John, A., and R. Pecchenino [1994], John, A., et al. [1995], Howarth, R. [1996], Fisher, E. O'N., and C. van MARREWIJK [1998]). The main result is that environmental taxation implies such a welfare loss for the generations experiencing the ETR that its implementation can not be wished. The generation which would design the policy would also bear the heaviest burden. This result originates in the fact that balanced ETRs have generally not been considered. This negative result for the political feasibility is here generalized to a balanced-budget reform.

We now briefly discuss the distributive effects of the policy between consumptions when young and old at the stable steady state. Could the ETR not only improve aggregate consumption but also both $\bar{c}$ and $\bar{d}$ ? Proposition 3 establishes that the ETR leads to a double dividend. In addition, if both $\bar{c}$ and $\bar{d}$ rise, the ETR verifies the intragenerational equity principle. We show that these three goals could be reached simultaneously. Under some mild adding conditions, ${ }^{10}$ environmental quality, consumptions when young

9. This assessement is formally proved in Appendix A.

10. See Appendix B for technical details. 
and old become larger. Note that this requires a sufficiently low debt-output ratio. Otherwise, the increase of the environmental tax rate that decreases the return of assets, directly and through the increase of capital, implies a too large decrease of the remunerated debt. In this case, remunerated savings, i.e. consumption when old, decreases.

\section{ETR Balanced by Debt-Output Ratio}

In this section, we consider an alternative policy. Given an appropriate level of abatement over output, we still investigate the effect of an increase of the environmental tax rate. However, to balance the government budget, the debt-output ratio will vary, keeping now the labor income tax rate as fixed. We will investigate whether such a policy may induce both the positive environmental and macroeconomic effects at the stable steady state.

To be more specific, we consider that following an increase of $\tau^{e}$, the government budget is balanced by a modification of $\delta$, taking the labor income tax rate as constant. Differentiating (17) with $d \tau^{w}=d g=0$ taking into account that $\bar{z}$ is given by (12), the policy change is described as:

$$
\left.\frac{d \delta}{d \tau^{e}}\right|_{d \tau^{w}=d g=0}=-\frac{\partial \tau\left(\tau^{e}, g, \delta\right) / \partial \tau^{e}}{\partial \tau\left(\tau^{e}, g, \delta\right) / \partial \delta}
$$

Using (10) and (14), we note that debt-output ratio affects aggregate consumption and environmental quality only through the investment rate $z$. This allows to prove the following proposition:

Proposition 4. Assume that $\tau^{w}$ and $g$ do not vary, $g<1-\alpha$ and $\frac{\beta}{1+\beta}<4 \alpha(1-\alpha)$. Following a rise of the environmental tax rate $\tau^{e}$, if $\tau^{e}>1-(1-g) \beta / \alpha$, there is $\hat{\delta} \in(0, \bar{\delta})$, such that $\bar{z}$ is increasing for all $\delta<\hat{\delta}$ through a decrease of $\delta$. This ETR produces positive environmental and macroeconomic effects if and only if:

(i) The public emission abatement over output is large enough, i.e. $g>\varepsilon / \theta$;

(ii) There is under-accumulation, i.e. $\delta \in\left(\delta_{g}, \hat{\delta}\right)$.

Proof. We start by investigating the effect of the increase of $\tau^{e}$ on $\bar{z}$. We note that:

$$
\left.\frac{d \bar{z}}{d \tau^{e}}\right|_{d \tau^{w}=d g=0}=\frac{\partial \zeta\left(\tau^{e}, g, \delta\right)}{\partial \tau^{e}}+\left.\frac{\partial \zeta\left(\tau^{e}, g, \delta\right)}{\partial \delta} \frac{d \delta}{d \tau^{e}}\right|_{d \tau^{w}=d g=0}
$$

where $\partial \zeta\left(\tau^{e}, g, \delta\right) / \partial \tau^{e}>0$ is given by (18) and 


$$
\frac{\partial \zeta\left(\tau^{e}, g, \delta\right)}{\partial \delta}=-\frac{\bar{z}+\alpha \beta\left(1-\tau^{e}\right)}{\sqrt{\left\{\beta\left[1-g-\left(1-\tau^{e}\right) \alpha\right]-\delta\right\}^{2}-4 \alpha \beta \delta\left(1-\tau^{e}\right)(1+\beta)}}<0 .
$$

Therefore, a sufficient condition to have $d \bar{z} / d \tau^{e}>0$ is $d \delta / d \tau^{e}<0$. Using (19) and (22), we deduce that $d \delta / d \tau^{e}$ and $\partial \tau\left(\tau^{e}, g, \delta\right) / \partial \delta$ have the same sign. The derivative of (17) with respect to the debt-output ratio taking into account that $\bar{z}$ is given by (12) gives:

$$
\frac{\partial \tau\left(\tau^{e}, g, \delta\right)}{\partial \delta}=\frac{\alpha}{1-\alpha} \frac{1}{\bar{z}}\left(1-\frac{\delta}{\bar{z}} \frac{\partial \zeta\left(\tau^{e}, g, \delta\right)}{\partial \delta}\right)-\frac{1}{\left(1-\tau^{e}\right)(1-\alpha)}
$$

Using (23) and (24), $\partial \tau\left(\tau^{e}, g, \delta\right) / \partial \delta<0$ is equivalent to $\psi(\delta)<1$, with:

$$
\psi(\delta) \equiv \frac{\alpha\left(1-\tau^{e}\right)}{\bar{z}}\left[1+\delta \frac{1+\alpha\left(1-\tau^{e}\right) \beta / \bar{z}}{\sqrt{\left[\beta\left[1-g-\alpha\left(1-\tau^{e}\right)\right]-\delta\right]^{2}-4 \alpha \beta \delta\left(1-\tau^{e}\right)(1+\beta)}}\right] .
$$

We can easily show that $\psi^{\prime}(\delta)>0$. Moreover, using (12), we have:

$$
\begin{aligned}
\psi(\bar{\delta}) & =+\infty \\
\psi(0) & =\frac{\alpha(1+\beta)\left(1-\tau^{e}\right)}{\beta\left[1-g-\alpha\left(1-\tau^{e}\right)\right]} .
\end{aligned}
$$

Therefore, if $\psi(0)<1$, there exists $\hat{\delta} \in(0, \bar{\delta})$ such that $\psi(\delta)<1$ for all $\delta<\hat{\delta}$. Hence, there is an increase of $\bar{z}$ through a decrease of $\delta$.

Then, applying the arguments of the proof of Proposition 3, we deduce that, using equation (20), the positive environmental effect is obtained if and only if $g>\varepsilon / \theta$ and, using equation (21), the macroeconomic effect is obtained if and only if $\delta \in\left(\delta_{g}, \hat{\delta}\right)$ because $\hat{\delta}<\bar{\delta}^{11}$

We obtain here a similar result than in Proposition 3, considering a different fiscal policy, i.e. a larger environmental tax rate implies a lower debt-output ratio, holding the labor income tax rate constant. The positive environmental and macroeconomic effects occur because this ETR raises $z$ (or $k$ ).

When a larger $\tau^{e}$ implies a lower debt-output ratio $\delta$, capital accumulation is accelerated, because even if the increase of the environmental tax rate has a negative effect on savings through its effect on the wage, the lower debt-output ratio reduces the

11. Note that the interval $\left(\delta_{g}, \hat{\delta}\right)$ may of course be non empty. For instance, the conditions required in Proposition 2 are in accordance with $\delta_{g} \leqslant 0$ for $1-(1-g) \beta / \alpha<\tau^{e} \leqslant 1-\frac{1-g}{\alpha \beta}[\beta-\alpha(1+\beta)]$. This requires $\alpha>\beta(1-\beta) /(1+\beta)$, which is satisfied for $\beta$ sufficiently close to 1 . 
usual crowding-out effect associated to debt. This last channel means that a larger share of savings is devoted to productive investment. Proposition 4 shows that the second effect may dominate.

This fiscal policy is especially interesting because it associates the improvement of aggregate consumption and environmental quality to a decrease of the debt-output ratio. Regarding the debt sustainability constraints faced by many countries today, this ETR gives rise to a third dividend.

\title{
VI. Conclusion
}

This paper examines the effects of ETR in an overlapping generations model by taking into account a debt stabilization constraint and public pollution abatement. We show that, when the budget-neutral reform allows a decrease in the income tax, the steady state investment factor increases. This result implies the (first) environmental dividend, i.e. an improvement of environmental quality, because of public abatement. On the other hand, the second (i.e. economic) dividend is obtained when the economy is characterized by under-accumulation of the capital stock. Finally, an increase of the environmental taxation budget-balanced by a variation of the debt-output ratio may also increase the environmental quality and the agents' consumption. More importantly, this fiscal policy not only brings about these two benefits but also reduces the debt-output ratio.

\section{Aknowledgenents}

The authors are indebted to two anonymous referees for their helpful suggestions and comments on an earlier version of this article.

\author{
Correspondence: \\ Mouez Fodha \\ PSE, University Paris 1 \\ 48 Bd Jourdan, \\ 75014 Paris, France \\ E-mail: mouez.fodha@gmail.com \\ Thomas Seegmuller \\ Aix-Marseille University, CNRS, EHESS, \\ Centrale Marseille, AMSE \\ E-mail:thomas.seegmuller@univ-amu.fr \\ Hiroaki Yamagami \\ Seikei University \\ E-mail:yamagami@econ.seikei.ac.jp
}




\section{Appendix}

\section{A. Intergenerational Distributive Issue}

Proposition 5. Assume that $\delta$ and $g$ do not vary, $\delta \in\left(\delta_{g}, \bar{\delta}\right), \quad g<1-\alpha$, $\frac{\beta}{1+\beta}<4 \alpha(1-\alpha), g>\varepsilon / \theta$ and the initial condition $z_{0}>\underline{z}$ is satisfied. Following an increase of $\tau^{e}$ at date $t_{0}$, the positive effects of the ETR fails at $t=t_{0}$, but there exists a date $t_{1}>t_{0}$ such that for all $t>t_{1}$, they occur.

Proof. Assume that $\tau^{e}$ increases permanently at $t=t_{0}$. By direct inspection of equation (7) and Figure 1 , we deduce that $z_{t}$ raises for all $t \geqslant t_{0}+1$ and converges to the stable steady state. Since $k_{t+1}=z_{t+1} k_{t}^{\alpha}$, the same happens for $k_{t}$ for all $t \geqslant t_{0}+1$.

At $t=t_{0}$, we have $c_{t}+d_{t}=(1-g) k_{t}^{\alpha}-k_{t+1}=k_{t}^{\alpha}\left(1-g-z_{t+1}\right)$. Since $k_{t}$ is predetermined and $z_{t+1}$ increases, aggregate consumption falls, which means that the positive effects of the ETR fail.

Considering now that $t \geqslant t_{0}+1, d\left(c_{t}+d_{t}\right)=(1-g) \alpha k_{t}^{\alpha-1} d k_{t}-d k_{t+1}$. For $t$ sufficiently large, namely $t>\tilde{t}$, the capital stock is characterized by under-accumulation, ${ }^{12}$ i.e. we have $(1-g) \alpha k_{t}^{\alpha-1}>1$, which implies that $d\left(c_{t}+d_{t}\right)>d k_{t}\left(1-\frac{d k_{t+1}}{d k_{t}}\right)$. Since at a stable equilibrium with $z_{t}=\bar{z}$ we have $k_{t+1}=\bar{z} k_{t}^{\alpha}$, there exists $t>\hat{t}$ such that $d k_{t+1} / d k_{t}<1$.

Therefore, when $t>t_{1}=\max \{\tilde{t}, \hat{t}\}, d\left(c_{t}+d_{t}\right)>0$ because $d k_{t}>0$ for all $t \geqslant t_{0}+1$. Since $e_{t+1}=(1-\eta) e_{t}+(\theta g-\varepsilon) k_{t}^{\alpha}$ also raises, the positive effects of the ETR apply for all $t>t_{1}$.

\section{B. Intragenerational Distributive Issue}

Proposition 6. Assume that $\delta$ and $g$ do not vary, $1-\alpha>g>\max \{\varepsilon / \theta$, $\left.1-\alpha-\frac{\alpha^{2}}{1-\alpha}\right\}, \frac{\beta}{1+\beta}<4 \alpha(1-\alpha)$ and $\tau^{e}<\alpha-\frac{1-\alpha}{\alpha}(1-g-\alpha)$. Following an increase of $\tau^{e}$, there exists $\tilde{\delta}>0$, such that for all $\delta \in\left(\delta_{g}, \min \{\tilde{\delta}, \bar{\delta}\}\right)$, the consumption of young $\bar{c}$ is increasing at the stable steady state, and the consumption of old $\bar{d}$ is increasing in $\tau^{e}$ too.

Proof. At the stable steady state, consumption when young $\bar{c}$ is given by:

$$
\bar{c}=\frac{1}{1+\beta} \bar{k}^{\alpha}\left[1-g-\alpha+\alpha \tau^{e}+\delta-\frac{\alpha \delta\left(1-\tau^{e}\right)}{\bar{z}}\right] .
$$

12. This is always the case if the sequence of $\left(k_{t}\right)$ is increasing through time. 
Because $\partial \bar{z} / \partial \tau^{e}>0$ (see Proposition 3) and $\bar{k}=\bar{z}^{-1 /(1-\alpha)}$, we deduce that $\partial \bar{c} / \partial \tau^{e}>0$.

Using the fact that savings is equal to $\bar{k}+\delta \bar{y}$, consumption when old $\bar{d}$ is equal to:

$$
\bar{d}=\left(1-\tau^{e}\right) \alpha\left(\bar{z} \frac{\alpha}{1-\alpha}+\delta \bar{z} \frac{2 \alpha-1}{1-\alpha}\right)
$$

For $\delta=0$, we have $\partial \bar{z} / \partial \tau^{e}=\alpha \bar{z} /\left[1-g-\left(1-\tau^{e}\right) \alpha\right]$. We deduce that:

$$
\frac{\partial \bar{d}}{\partial \tau^{e}}=\frac{\alpha \bar{z} \frac{\alpha}{1-\alpha}}{(1-\alpha)\left[1-g-\left(1-\tau^{e}\right) \alpha\right]}\left[\alpha^{2}-(1-\alpha)(1-g-\alpha)-\alpha \tau^{e}\right] .
$$

Therefore, for $\delta=0, \partial \bar{d} / \partial \tau^{e}>0$ if and only if $1-g-\alpha<\frac{\alpha^{2}}{1-\alpha}$, or equivalently $1-\alpha>g>1-\alpha-\frac{\alpha^{2}}{1-\alpha}$, and $\tau^{e}<\alpha-\frac{1-\alpha}{\alpha}(1-g-\alpha)$.

In this case, by continuity and to be in accordance with Proposition 3 , there exists $\tilde{\delta}>0$, such that for all $\delta \in\left(\delta_{g}, \min \{\tilde{\delta}, \bar{\delta}\}\right),{ }^{13}$ we have $\partial \bar{d} / \partial \tau^{e}>0$.

\section{References}

Abel, A., G. Mankiw, L. Summers, and R. Zeckhauser (1989): “Assessing Dynamic Efficiency: Theory and Evidence”, Review of Economic Studies, 56, 1-19.

Bosello, F., C. Carraro, and M. Galeotti (2001): "The double dividend issue: modeling strategies and empirical findings", Environment and Development Economics, 6, 9-45.

Bovenberg, A.L., and B.J. Heijdra (1998): "Environmental Tax Policy and Intergenerational Distribution", Journal of Public Economics, 67, 1-24.

Bovenberg, A.L., and R.A. DE Moois (1994): "Environmental Levies and Distortionary Taxation", American Economic Review, 84, 1085-89.

Bovenberg, A.L., and F. van der Ploeg (1996): “Optimal Taxation, Public Goods and Environmental Policy with Involuntary Unemployment", Journal of Public Economics, 62, 59-83.

13. Note that this interval is non empty for $\tau^{e}$ lower or sufficiently close to $1-\frac{1-g}{\alpha \beta}[\beta-\alpha(1+\beta)]$. 
Chiroleu-Assouline, M., and M. Fodha (2005): “Double Dividend with Involuntary Unemployment: Efficiency and Intergenerational Equity", Environmental and Resource Economics, 31, 389-403.

Chiroleu-Assouline, M., and M. Fodha (2006): "Double Dividend Hypothesis, Golden Rule and Welfare Distribution", Journal of Environmental Economics and Management, 51, 323-335.

Chiroleu-Assouline, M., and M. Fodha (2014): "From Regressive Pollution Taxes to Progressive Environmental Tax Reforms", European Economic Review, 69, 126-142.

de la Croix, D., and P. Michel (2002): “A Theory of Economic Growth: Dynamics and Policy in Overlapping Generations", Cambridge University Press.

Fernández, E., P. Rafaela, and R. Jesús (2010): “Double Dividend, Dynamic Laffer Effects and Public Abatement", Economic Modelling, 27, 656-665.

Fisher, E. O’N., and C. van MarrewiJk (1998): "Pollution and Economic Growth", The Journal of International Trade \& Economic Development: An International and Comparative Review, 7, 55-69.

Fodha, M., and T. Seegmuller (2012): “A Note on Environmental Policy and Public Debt Stabilization", Macroeconomic Dynamics, 16, 477-492.

Fodha, M., and T. Seegmuller (2014): "Environmental Quality, Public Debt and Economic Development", Environmental and Resource Economics, 57, 487-504.

Goulder, L.H. (1995): “Environmental Taxation and the 'Double Dividend': A Reader's Guide", International Tax and Public Finance, 2, 157-183.

Heijdra, B.J., J.P. Kooman, and J E. Ligthart (2006): "Environmental Quality, the Macroeconomy, and Intergenerational Distribution", Resource and Energy Economics, 28, 74-104.

Howarth, R. (1996): “Climate Change And Overlapping Generations”, Contemporary Economic Policy, 14, 100-111.

John, A., and R. Pecchenino (1994): “An Overlapping Generations Model of Growth and Environment”, Economic Journal, 104, 1393-1410.

John, A., R. Pecchenino, D. Schimmelpfennig and S. Schreft (1995): "Short-lived Agents and the Long-lived Environment", Journal of Public Economics, 58, 127-141.

Ono, T. (2005): "Environmental-tax Financed Social Security Tax Cuts and the Double Dividends", Public Finance Analysis, 61, 178-200.

Parry, I.W.H. (1995): "Pollution Taxes and Revenue Recycling", Journal of Environmental Economics and Management, 29(3), 64-77. 
Proost, S., and D. Van Regemorter (1995): "The Double Dividend and the Role of Inequality Aversion and Macroeconomic Regimes", International Tax and Public Finance, 2, 207-219.

Rausch, S. (2013): "Fiscal Consolidation and Climate Policy: an Overlapping Generations Perspective", Energy Economics, 40, 134-148. 